\title{
Raman and Surface-Enhanced Raman Scattering Spectroscopy of Bis-Netropsins and Their DNA Complexes
}

\section{MIKHAIL ERMISHOV, ${ }^{12}$ ALYONA SUKHANOVA, ${ }^{12}$ EVCENIY KRYUKOV, ${ }^{2}$ SERGE GROKHOVSKY, ${ }^{3}$ * ALEXE ZHUZE, ${ }^{3}$ VLADIMIR OLEINIKOV, ${ }^{2}$ JEAN CLAUDE JARDILLIER, ${ }^{1}$ IGOR NABIEV ${ }^{1}$}

${ }^{1}$ EA2063, Institut Federatif de Recherche No. 53, Biomolecules, UFR de Pharmacie, Universite de Reims ChampagneArdenne, 51100 Reims, France

Shemyakin \& Ovchinnikov Institute of Bioorganic Chemistry, Russian Academy of Sciences, Moscow 117871, Russia

${ }^{3}$ Engelhardt Institute of Molecular Biology, Russian Academy of Sciences, Moscow 117984, Russia

${ }^{4}$ Center for Medical Studies, University of Oslo, Oslo, Norway

Received 19 January 2000; revised 14 March 2000; accepted 4 April 2000

Published online 17 July 2000

\begin{abstract}
The interactions of three bis-netropsins (bis-Nts), which are potent catalytic inhibitors of DNA-binding enzymes, with three double-stranded oligonucleotides (OLIGs), which contain sites of different specific affinities for each bis-Nt, were analyzed. Raman spectroscopy was performed for selective monitoring of modifications of the bis-Nt or the OLIG structure upon bis-Nt-DNA binding, and surface-enhanced Raman scattering spectroscopy (SERS) was an additional tool for topology studies of ligand-DNA complexes. The spectral data showed conformational changes of both partners (bis-Nt and OLIG) upon complexation. Structural variations of bis-Nts appeared to be dependent on a bis-Nt-OLIG binding constant and were found to be small in the specific DNA binding and highest for nonspecific binding of bis-Nt with the corresponding OLIG. The conformational changes of the OLIGs were varied with a bis-Nt-OLIG binding constant in the same manner. The bis-Nts seemed to induce a perturbation in the OLIG's structure, as well as in the positions of their direct binding. These DNA structural modification effects may explain the inhibition of DNA-binding enzymes in the variety of very distinct DNA-enzyme binding sites by bis-Nts reported previously. (C) 2000 John Wiley \& Sons, Inc. Biopolymers (Biospectroscopy) 57: 272-281, 2000
\end{abstract}

Keywords DNA-ligand interactions; bis-netropsins; Raman scattering spectroscopy; surface-enhanced Raman spectroscopy; anticancer drugs

\section{INTRODUCTION}

The well-known antibiotic netropsin $(\mathrm{Nt})$ and its derivatives bind noncovalently to AT-rich double-

Correspondence to: I. Nabiev (igor@hexanet.fr).

Contract grant sponsor: NATO; contract grant number: HT974608.

Contract grant sponsor: Association pour la Recherche Contre le Cancer (France); contract grant number: 9523.

Contract grant sponsor: ARERS (France).

Contract grant sponsor: INTAS (European Community); contract grant number: 97-0522.

Contract grant sponsor: RFBR (Russia); contract grant numbers: 98-04-49220, 98-03-32949.

Biopolymers (Biospectroscopy). Vol. 57, 272-281 (2000)

(C) 2000 John Wiley \& Sons. Iroc. stranded DNA stretches ${ }^{1}$ and are capable of inhibiting numerous DNA-binding enzymes such as gyrase, human DNA topoisomerases I and II, DNAse, and so forth. The DNA binding of these classical nonintercalators is extremely sequence specific. The Nts bind to DNA within the minor groove through the hydrogen bonds between nitrogen atoms of their amide groups (Fig. 1) and 02 atoms of thymines and/or N3 atoms of adenines of DNA. This molecular mechanism of ATspecific DNA binding by the $\mathrm{Nts}$, which was first proposed by Zasedatelev et al. ${ }^{2,3}$ and later confirmed by X-ray analysis ${ }^{4,5}$ and NMR spectroscopy, ${ }^{6-8}$ served as a theoretical basis for synthesis 

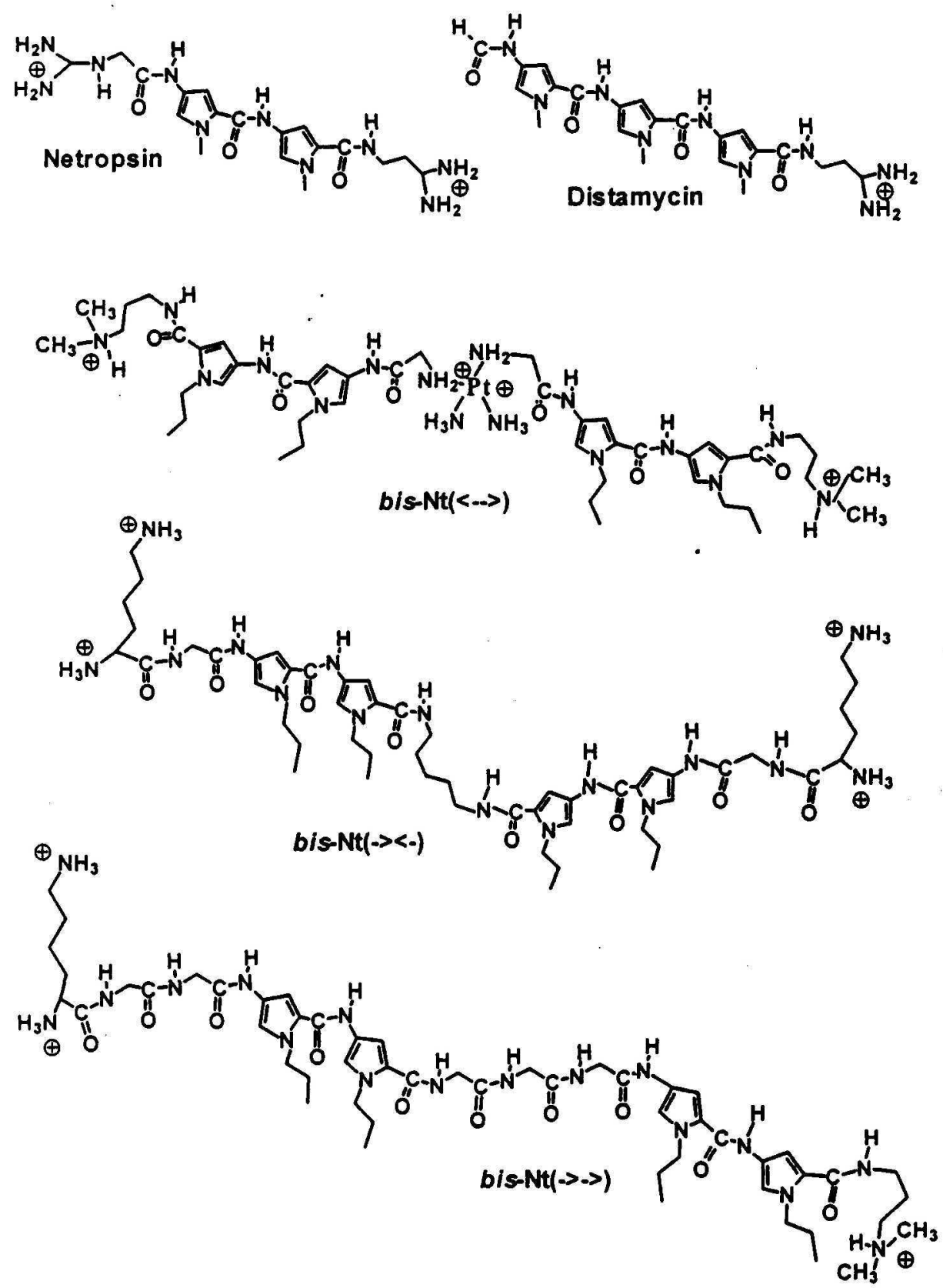

Figure 1. The chemical structures of netropsin, distamycin, and bis-netropsins.

of novel Nt analogs (bis-Nts) consisting of two Nt moieties linked with a flexible spacer. ${ }^{9,10}$ The bisNts cover a whole turn of the DNA double helix, and the specificity of their binding rises dramatically. ${ }^{11}{ }^{12}$

Recent studies demonstrated that certain bisNts possess a several-fold higher antitumor and antiviral activity than $\mathrm{Nt}$ that is due to modulation or inhibition of the different DNA-binding enzymes. ${ }^{13-15}$ We previously synthesized a series of high sequence-specific bis-Nts ${ }^{16}$ and analyzed their ability to bind DNA and inhibit a number of DNA-directed enzymes. ${ }^{9,11}$ Very recently we described a few effects of several new bis-Nts on the human DNA topoisomerase I, an important clinical target of antitumor drugs: the disappearance of some of the topoisomerase I specific DNA cleavage sites; enhancement of some other sites; and, moreover, induction of the new DNA cleavage sites by the bis-Nts. ${ }^{14}$ All these effects that deter- 
mine the potential of bis-Nts for inhibition of human topoisomerase I and, consequently, their antitumor activity, require detailed analysis of the structural features induced by these ligands on the DNA level. Although the 3-dimensional structures of Nt complexes with DNA are established, no structural data exist on molecular interactions of bis-Nts within the DNA complexes.

This article presents the first Raman and surface-enhanced Raman scattering (SERS) spectroscopy study of three new antitumor bis-Nts [bis-Nt(<->), bis-Nt(-><-), and bis-Nt(->->), Fig. 1] and their complexes with three different 20 -mer double-stranded oligonucleotides (OLIGs). The sequence of each OLIG provides at least a 10-fold higher binding constant for one of the bis-Nts studied. ${ }^{17,18}$ The spectral data analysis enabled the characterization of structural modifications of the bis-Nts and the OLIGs upon their specific or nonspecific binding.

\section{MATERIALS AND METHODS}

\section{Chemicals}

The bis-Nt(<->) was synthesized as described in the literature. ${ }^{16}$ Synthesis of bis-Nt(-><-) and bis$\mathrm{Nt}(->->)$ will be published in the future.

Single-stranded oligonucleotides 5'-CAAAGACTTAGTTTTAAAAA-3' [1], 5-TTTTTAAAACTAAGTCTTTG-3' [2], 5'-CAAAGACTTAGAAAATTTTT-3' [3], 5'-AAAAATTTTCTAAGTCTTTG-3' [4], 5'-CAAAGACTTAGAAAAAAAAA-3' [5], and 5^TTTTTTTTTCTAAGTCTTTG-3' [6] were synthesized by Eurogentek (Belgium) and purified by polyacrylamide gel electrophoresis as described by Sambrook et al. ${ }^{19}$ The double-stranded oligomers (OLIGs) [1] + [2], [3] + [4], and [5] + [6] were prepared by mixing equal molar quantities of two complementary strands in the water. These mixtures were annealed at $95^{\mathrm{e}} \mathrm{C}$ for $15 \mathrm{~min}$ followed by overnight cooling to room temperature. Then the solutions were evaporated to dryness and dissolved in TE buffer $(10 \mathrm{mM}$ Tris- $\mathrm{HCl}, \mathrm{pH}$ 8.0, $1 \mathrm{mM}$ EDTA) to a final concentration of 1.2 $\mathrm{mM}$. The quality of annealing was tested by UVvis and polarized fluorescence spectroscopy as described in the literature. ${ }^{17}$ The data showed $100 \%$ formation of double-stranded oligomers. LigandOLIG complexes were prepared by mixing equal molar quantities of bis-Nt and OLIG.

The concentrations of the OLIGs were determined by UV-vis, using a molar extinction coeffi- cient $\left(\mathrm{e}_{260}=13,200 \mathrm{M}^{-1} \mathrm{~cm}^{-1}\right)$ calculated for $1 \mathrm{bp}$ of the OLIGs. The same method was used for the measurement of bis-Nt concentrations with a molar extinction coefficient (6305) of 40,000 $M^{l}$ $\mathrm{cm}^{-1} .{ }^{17}$ The $50-\mathrm{m}$.L final stock solutions of nucleotides were used for preparation of the complexes and further spectral measurements.

The OLIGs [1] + [2] (OLIGl), [3] + [4] (OLIG2), and [5] + [6] (OLIG3) are known as "specific" for the binding of bis- $\mathrm{Nt}(<->)$, bis$\mathrm{Nt}(-><-)$, and bis-Nt(->->), respectively, and "nonspecific" for each of the two other bis-Nts. The specificity is determined by the fact that the binding constants of bis-Nt( $<->)$ with OLIGl, bis$\mathrm{Nt}(-><-)$ with OLIG2, and bis-Nt(->->) with OLIG3 (specific binding) are at least 10-fold higher than their corresponding binding constants with each of the two other OLIGs (nonspecific binding).

\section{Raman and SERS Spectroscopy}

Raman and SERS spectra were recorded with a Ramanor HG-2S (Jobin Yvon) spectrometer; a 514.5-nm line of an argon laser (Spectra Physics, model 164-03) was used for excitation. The irradiation power on the sample did not exceed 30 $\mathrm{mW}$ in the SERS and $200 \mathrm{~mW}$ in the Raman scattering experiments. All spectra were registered with scanning at a $1 \mathrm{~cm}^{-1}$ step and an integration time of each point of $0.7 \mathrm{~s}$ for SERS and $3 \mathrm{~s}$ for Raman spectra.

Silver hydrosol was prepared by reduction of silver nitrate with sodium citrate and was used as a SERS-active substrate as described by Ianoul et al. $^{20}$

The data accumulation of 10 independent scans with time averaging was used for Raman spectra recording. The stability of the samples during laser irradiation was controlled by comparison of the spectra as a function of time. The spectra of free (unbound) bis-Nts and OLIGs were obtained by subtracting the spectrum of the buffer from the corresponding bis-Nt-buffer and OLIG-buffer spectra. The spectra of bis-NtOLIG complexes were obtained by the same procedure. The standard buffer spectrum was subtracted from the experimental spectra until the water band at $1645 \mathrm{c} \mathrm{m}^{-1}$ was removed. The spectra were treated with LabCalc (Galactic Industries) software as described in the literature. ${ }^{21}$ 
Table I. Assignments of Bands in Raman Spectra of Netropsin (Nt) and Bis-Nt

\begin{tabular}{|c|c|c|c|c|c|}
\hline \multicolumn{4}{|c|}{ Observed Frequencies $\left(\mathrm{cm}^{-1}\right)$} & \multirow{2}{*}{$\begin{array}{c}\begin{array}{c}\text { Calculated } \\
\text { Frequencies } \\
\left(\mathrm{cm}^{-1}\right)\end{array} \\
\text { Bis-Nt }\end{array}$} & \multirow[b]{2}{*}{ Assignment } \\
\hline Bis-Nt(↔) & Bis-Nt $(\rightarrow \leftarrow)$ & Bis-Nt $(\rightarrow \rightarrow)$ & $\mathrm{Nt}^{\mathrm{a}}$ & & \\
\hline 1007 & 1007 & 1007 & 1010 & 1007 & Ring $(P 6)^{c}$ in-plane vibration \\
\hline 1033 & 1033 & 1033 & & 1041 & $\mathrm{C}-\mathrm{C}$ stretching \\
\hline 1089 & 1090 & 1087 & 1066 & $1087^{d}$ & $\begin{array}{l}\text { Ring (P5) in-plane vibration } \\
\text { Interplane } \mathrm{C}-\mathrm{H} \text { bend and }\end{array}$ \\
\hline 1148 & 1146 & 1146 & 1145 & & $\begin{array}{l}\text { stretch } \\
\text { Interplane } \mathrm{C}-\mathrm{H} \text { bend and }\end{array}$ \\
\hline 1160 & 1159 & 1160 & & & $\begin{array}{l}\text { stretch } \\
\text { Interplane } \mathrm{C}-\mathrm{H} \text { bend and }\end{array}$ \\
\hline 1196 & 1196 & 1196 & 1209 & . & $\begin{array}{l}\text { stretch } \\
\text { Breathe ring in-plane }\end{array}$ \\
\hline 1235 & 1237 & 1235 & 1230 & 1230 & vibration \\
\hline 1273 & 1278 & 1270 & 1278 & 1278 & $\begin{array}{l}\text { Amide III } \\
\mathrm{C}-\mathrm{C}, \mathrm{C}=\mathrm{C} \text { ring stretch in }\end{array}$ \\
\hline 1362 & 1352 & 1362 & 1354 & 1359 & plane \\
\hline 1405 & 1406 & 1407 & & 1392 & $\mathrm{C}-\mathrm{N}$ ring stretch \\
\hline 1422 & 1422 & 1420 & 1412 & 1420 & $\begin{array}{l}\text { Ring }(\mathrm{P} 4)^{c} \text { in-plane vibration } \\
\text { Ring }(\mathrm{P} 3)^{c} \text { out of plane }\end{array}$ \\
\hline 1450 & 1450 & 1446 & 1440 & $1448^{d}$ & $\begin{array}{l}\text { vibrations } \\
\text { Ring }(P 2)^{c} \text { out of plane }\end{array}$ \\
\hline 1478 & 1479 & 1478 & 1477 & $1470^{d}$ & vibrations \\
\hline 1560 & 1560 & 1560 & & $1554^{d}$ & $\begin{array}{l}\text { Ring in-plane vibration } \\
\text { Amide II + ring }(\mathrm{P} 1)^{c} \text { in-plane }\end{array}$ \\
\hline 1578 & 1579 & 1578 & 1583 & $1584^{d}$ & vibration \\
\hline 1618 & 1622 & 1623 & $1620-1640$ & 1625 & Amide I \\
\hline
\end{tabular}

The data are from Refs. 22 and 23.

- The frequencies were calculated for the fragment of bis- $\mathrm{Nt}$ containing pyrrole, peptide, and propyl groups.

c The notation is from Ref. 23.

d Vibrations are sensitive to the interaction of the pyrrole ring hydrogen and oligonucleotide.

\section{RESULTS AND DISCUSSION}

Raman and SERS Spectra of Bis-Nts in Solution

Assignments of almost all the bands in the Raman spectra of Nt and distamycin (Dst) were published previously. ${ }^{22,23}$ The majority of these bands are assigned to the vibrations of the pyrrole rings and the amide groups of the drugs. Because the main spectral features of bis-Nts and $\mathrm{Nt}$ are very similar, the interpretation of the Ramanactive modes of bis-Nts may certainly be based on those for $\mathrm{Nt}$ (Table I). The only remarkable difference between the Nt spectrum published previously and the bis-Nts spectra recorded in our work is localized in the $1060-1090 \mathrm{~cm}^{-1}$ spectral region. Our computer modeling of the vibrational modes of bis-Nts shows that the upshift of the band at $1066(\mathrm{Nt})$ to $1090 \mathrm{~cm}^{-1}$ (bis-Nt) is due to the propyl groups at the $\mathrm{N}$ position of the bis- $\mathrm{Nt}$ pyrrole rings (instead of the methyl groups of $\mathrm{Nt}$ ). We also found that the bands at 1090, 1420, 1450, 1478 , and $1578 \mathrm{~cm}^{-1}$ are mainly determined by vibrations of the hydrogen of the pyrrole ring.

The characteristic bands in the Raman and SERS spectra of bis-Nts (Fig. 2) are largely coincidental. The resemblance of these spectra indicates that the electromagnetic mechanism dominates in the total surface-induced enhancement. This mechanism should not be related to chemisorption of the bis-Nt molecule and distortion of its conformation. ${ }^{24}$ This fact allows the interpretation of SERS spectra to be based on the assignment of Raman bands (Table I). A thorough comparison of the Raman and SERS spectra revealed the differences in the relative intensities of bands bearing information on the orientation of the mol- 


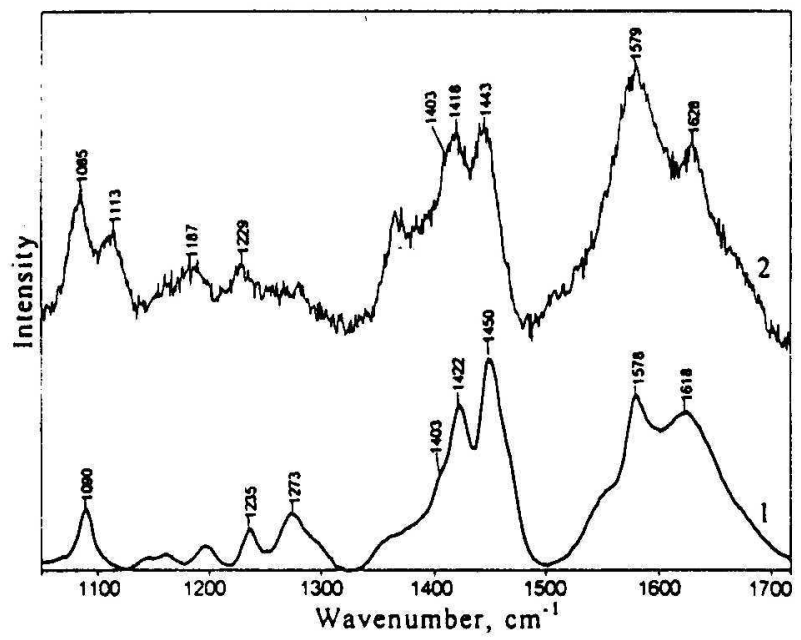

Figure 2. Raman (spectrum 1) and SERS (spectrum 2) spectra of bis-Nt( $\leftrightarrow$ ). See the Materials and Methods section for details.

ecule relative to the SERS-active surface. In particular, the relative intensities of vibrations of the pyrrole ring at $626,1085,1404$, and $1579 \mathrm{~cm}^{-1}$ are increased in the SERS spectrum, compared with the corresponding Raman spectrum. So, we can conclude that the bis-Nts adsorb on the SERS-active surface via their pyrrole rings. Therefore, the plane of the pyrrole ring is not expected to be parallel to the SERS-active surface, because in this case the enhancement of the ring vibrations due to the electromagnetic field component normal to the surface would be minimal. ${ }^{25}$

The doublet at $1404 / 1444 \mathrm{~cm} \backslash$ which can be used for evaluation of the access of the molecule to the SERS-active surface, ${ }^{30}$ is particularly illustrative in a comparison of Raman and SERS spectra. For example, the ratio of the bands at 1404 and $1444 \mathrm{~cm}^{-1}$ is 0.5 in the Raman spectrum and 0.9 in the SERS spectrum. An increase in the intensity of the $\mathrm{C}-\mathrm{N}$ vibration of the pyrrole ring at $1404 \mathrm{c} \mathrm{m}^{-1}$ relative to the ring vibration at 1444 $\mathrm{cm}^{-1}\left(\mathrm{I}_{1404} / \mathrm{I}_{1444}\right)$ should be determined by reorientation of bis-Nt molecules upon interaction with the SERS-active surface. ${ }^{30}$ Consequently, this parameter $\left(\mathrm{I}_{1404} / \mathrm{I}_{1444}\right)$ may be used for identification of the orientation of the pyrrole rings of bis-Nts in their complexes with DNA.

\section{Raman Spectra of Oligonucleotides in Solution}

Three OLIGs, each containing the AT-rich sequence specific for only one of the three bis- $\mathrm{Nt}$ molecules, ${ }^{16} 18$ were used in the Raman experiments. The Raman spectra show that all three OLIGs are in the B conformation. The spectra of both free and bis-Nt-bound OLIGs contain B-form marker bands at $838 \mathrm{~cm}^{-1}(-\mathrm{O}-\mathrm{P}-\mathrm{O}-$ antisymmetric stretch) and $1090 \mathrm{~cm}^{-1}\left(\mathrm{PO}_{2}^{-}\right.$symmetric stretch). ${ }^{26}$

\section{Modifications of Bis-Nts Structure upon DNA Binding}

Figures 3-5 show the Raman spectra of free bis$\mathrm{Nts}$, as well, as the spectra of bis- $\mathrm{Nt}(<->)$, bis$\mathrm{Nt}(-><-)$, and bis-Nt(->->) bound with OLIGl, OLIG2, and OLIG3, respectively. The major differences in the spectra are observed in the regions of amide and pyrrole vibrations summarized in Table II.

The amide I region (1610-1670 $\left.\mathrm{cm}^{-1}\right)$ reflects modifications of the bis-Nt structures induced by DNA binding. The analysis of the spectra revealed that interaction with the DNA resulted in upshifts of the amide I bands of the bis-Nts. For each bis-Nt studied, this upshift was the smallest for specific substrate binding and much larger when nonspecific sequences were employed (Table II). The most prominent changes were found for bis-Nt(-><-)-OLIGs complexes: OLIG2 (specific) binding results in a $11 \mathrm{~cm}^{-1}$ shift of the amide I band $\left(1622 \mathrm{~cm}^{-1}\right)$, whereas OLIGs 1 and 3 (nonspecific) induce a $29 \mathrm{~cm}^{-1}$ shift of the same band. The least changes were observed for bis-

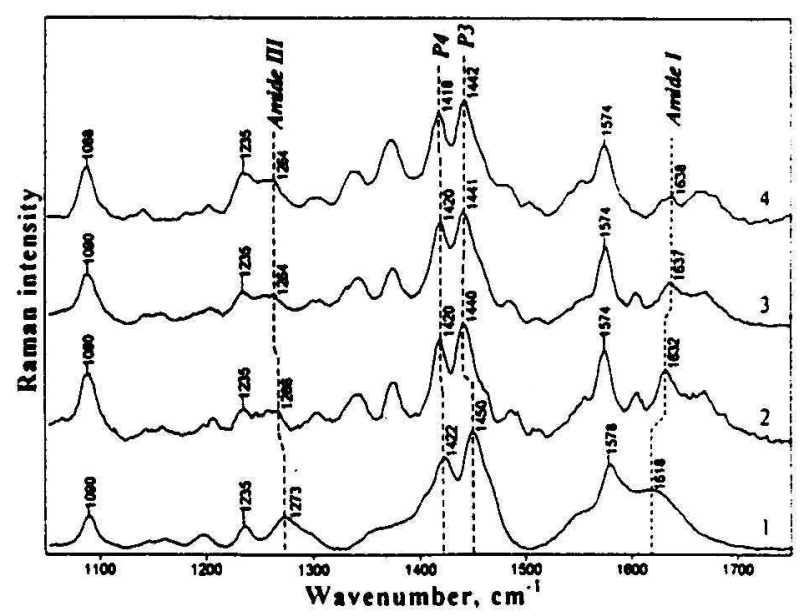

Figure 3. Raman spectra of bis-Nt( $\leftrightarrow)$ and bis$\mathrm{Nt}(\leftrightarrow)$-oligonucleotide complexes: bis- $\mathrm{Nt}(\leftrightarrow)$ (spectrum 1), bis-Nt( $\leftrightarrow$ )-OLIG1 complex (spectrum 2), bis-Nt $(\leftrightarrow)-$ OLIG2 complex (spectrum 3), and bis-Nt( $\leftrightarrow$ )-OLIG3 complex (spectrum 4). See Figure 1. for the notations. 
Table II. Positions and Frequency Shifts $\left(\mathrm{cm}^{-1}\right.$ ) of Amides I and III Raman Bands of Bis-Netropsin (Bis-Nt) Induced by DNA Binding

\begin{tabular}{|c|c|c|c|c|c|c|}
\hline & \multicolumn{2}{|c|}{ Bis-Nt $(\leftrightarrow)$} & \multicolumn{2}{|c|}{ Bis-Nt $(\rightarrow \leftarrow)$} & \multicolumn{2}{|c|}{ Bis-Nt( $\rightarrow \rightarrow)$} \\
\hline & Amide I & Amide III & Amide I & Amide III & Amide I & Amide III \\
\hline Unbound & 1618 & 1273 & 1622 & 1278 & 1623 & 1270 \\
\hline OLIG1 & $1632(14)$ & $1266(7)$ & $1650(28)$ & $1261(17)$ & $1639(16)$ & 1258 (12) \\
\hline OLIG2 & 1637 (19) & $1264(9)$ & $1633(11)$ & $1264(12)$ & $1639(16)$ & $1260(10)$ \\
\hline OLIG3 & $1638(20)$ & $1264(9)$ & $1651(29)$ & $1261(17)$ & $1633(10)$ & 1265 (5) \\
\hline
\end{tabular}

The frequencies and shifts $\left(\mathrm{cm}^{-1}\right)$ of the amide bands in the Raman spectra of the bis-netropsin-(specific OLIG) complexes are in bold.

The shift $\left(\mathrm{cm}^{-1}\right)$ of the amide band in the spectra of the bis-netropsins-OLIGs complex relative to that in the spectra of corresponding unbound bis-netropsins is shown in parentheses.

vibration changed. The SERS spectrum of the bis-Nt $(\longrightarrow \rightarrow)-0$ LIG3 complex (specific binding) was only a superposition of the SERS spectra of the components without any noticeable spectral modifications.

The SERS data suggested that the pyrrole rings of bis-Nts in complex with DNA assume various orientations, so the angles and directions of turns of the rings for these bis-Nts should be different. These differences in the direction of the turns for the two ligands were demonstrated by the character of the change in the $\mathrm{I}_{1404} / \mathrm{I}_{1444}$ ratio upon ligand binding to DNA: it decreased for bis$\mathrm{Nt}(<->)$ and increased for bis- $\mathrm{Nt}(-><-)$. Moreover, the magnitude of reorientation of the pyrroles was also different as judged from a change in the $\mathrm{I}_{1404} / \mathrm{I}_{1444}$ ratio. At the same time, the orientation of the pyrrole rings of bis- $\mathrm{Nt}(-\gg-\gg)$ was not affected by DNA binding.

All these results provided the evidence of several conformational features of bis-Nt-DNA complexes. The changes in amides I and III are consistent with $\mathrm{H}$ bonding of the bis-Nts to the DNA and modification of the torsion angle between the pyrrole groups. This conclusion was supported by the structure of Nt-DNA complexes ${ }^{4}$ and CD data on bis-Nt-DNA complexes. ${ }^{3}$ Moreover, the affinity of bis-Nt-DNA interaction determined by a DNA sequence was found to be in direct correlation with the shifts of positions of the amide I and amide III bands. The pyrrole ring vibrations were also affected by DNA binding. The frequency shifts of the pyrrole vibrations were associated with variations of the distribution of electron density caused by the interaction of the hydrogen of the bis-Nt NH groups with the oligonucleotide and by van der Waals interaction between the hydrogens of the pyrrole ring and the hydrogen atoms of the $\mathrm{C} 2$ adenine moiety. ${ }^{28}$ These alterations do not correlate with the specificity of drug binding and can serve as an indicator of bis-NtDNA interaction. Because bis-Nts are unlikely to intercalate, this observation implies that the direct interactions between other parts of the molecules and DNA induce stresses and alterations in the bond orbitals of pyrrole rings.

\section{Changes in Conformation of Oligonucleotides Induced by Bis-Nts Binding}

A number of important conformation-sensitive Raman markers of oligonucleotides are obscured by the strong Raman features of the bis-Nts. In fact, only a few spectral regions exist with negligible overlapping where unambiguous analysis of structural transitions in the OLIGs is possible. The Raman bands in the 670-680 and 1330$1340 \mathrm{~cm}^{-1}$ regions in particular are well-known spectroscopic markers of the OLIG structural alterations sensitive to the structure of the furanose ring pucker of the guanine bases. ${ }^{26} \mathrm{In}$ our study, analysis of this region seems extremely important because the conformational changes can be traced not only within the Nt-specific sequence (normally AAAA and TTTT motifs) but also in the vicinity of this sequence. The bands at 790 and $1206 \mathrm{~cm}^{-1}$ are sensitive to the backbone parameters and to the mutual base interaction, respectively. ${ }^{26}$

The change in the relative intensity of the 670 and $680 \mathrm{~cm}^{-1}$ bands is sensitive to the $\mathrm{C} 1$ '-exo$\mathrm{C} 2$ '-endo conformational transition of the sugar pucker of $\mathrm{dG}^{29}{ }^{29}$ Therefore, we compared these bands in the Raman spectra of different bis-NtOLIG complexes.

Prominent conformation changes of the gua- 
Table III. Alterations of Raman Bands of Oligonucleotides Near 680 and $1333 \mathrm{~cm}^{-1}$ Induced by Binding of Bis-Netropsin (Bis-Nt)

Bis-Nt $(\leftrightarrow) \quad$ Bis-Nt $(\rightarrow \leftarrow) \quad$ Bis- Nt $(\rightarrow \rightarrow)$

\begin{tabular}{llll} 
OLIG1 & $\frac{\mathrm{w}^{\mathrm{a}}}{\mathrm{w}^{\mathrm{b}}}$ & $\mathrm{m}$ & $\mathrm{m}$ \\
OLIG2 & $\mathrm{m}$ & $\underline{\mathrm{w}}$ & $\mathrm{vw}$ \\
& $\mathrm{m}$ & $\underline{\mathrm{w}}$ & $\mathrm{vw}$ \\
OLIG3 & $\mathrm{m}$ & $\mathrm{m}$ & $\mathrm{vw}$ \\
& $\mathrm{m}$ & $\mathrm{w}$ & $\underline{\mathrm{vw}}$ \\
\hline
\end{tabular}

The letters in the table show the relative intensity of the Raman bands at 680 and $1333 \mathrm{~cm}^{-1}$. The results for the binding of the bis-netropsins with their specific OLIGs are underlined.

- The intensity of the $\mathrm{C} 2$-endo/anti $\mathrm{dG}$ band $\left(680 \mathrm{~cm}^{-1}\right)$ in relation to the $\mathrm{C1}^{\prime}$-exolanti $\mathrm{dG}$ plus $\mathrm{C2}^{\prime}$-endo/anti $\mathrm{dT}$ bands $\left(670 \mathrm{~cm}^{-1}\right)$.

The intensity of the $\mathrm{C} 2$-endo/anti dG band $\left(1333 \mathrm{~cm}^{-1}\right)$ in relation to the $\mathrm{Cl}^{\prime}$-exolanti band $\left(1340 \mathrm{~cm}^{-1}\right)$ plus the band of the adenine vibration at $1342 \mathrm{~cm}^{-1}$.

nine-linked furanose ring were found when bis$\mathrm{Nt}(-><-)$ and bis-Nt(<->) were complexed with all three OLIGs, but DNA binding of bis-Nt(->->) did not result in any modifications within this region (Table III). The DNA binding of the first two bis-Nts was followed by a relative increase of the $680 \mathrm{c} \mathrm{m}^{-1}$ band. Yet this increase was stronger for bis-Nt( $<->)$-DNA than for bis-Nt(-><-)-DNA complexes.

Supporting evidence for previous interpretations was provided by analysis of the relative intensities within the $1333 / 1340 \mathrm{~cm}^{-1}$ doublet. This doublet is also characteristic for conformational changes involving the guanine bases so that the band at $1333 \mathrm{~cm}^{-1}$ corresponds to the $\mathrm{C} 2$ '-endo $\mathrm{dG}$ and the $1340 \mathrm{~cm}^{-1}$ is of a $C l^{\prime}$-exo $\mathrm{dG}$ conformation. ${ }^{29} \mathrm{As}$ in the previous case, the sugar pucker of $\mathrm{dG}$ is changed from a $\mathrm{Cl}^{\prime}$-exo to $\mathrm{C}^{\prime}$ endo conformation on DNA binding and the relative intensities in this doublet reflect the amount of furanose rings in the $C 1^{\prime}$-exo or $C 2^{\prime}$-endo conformation. If different bis-Nt-OLIG complexes are compared, the $C 2^{\prime}$-endo $\mathrm{dG}$ band is always the strongest for bis- $\mathrm{Nt}(<->)$-DNA complexes and weakest for the bis-Nt $(\longrightarrow \longrightarrow)$-DNA complexes. Typical spectral modifications induced by the bis$\mathrm{Nt}(\ll-»)$-OLIGl complexation are presented in Figure 6.

Our spectral data show that every bis-Nt studied induced local perturbations in the OLIG conformation. Moreover, these structural alterations were most significant when nonspecific DNA binding of a bis-Nt took place. In addition, bis$\mathrm{N}(\longrightarrow \rightarrow$ induced structural changes in OLIGs were much less significant than those due to other bis-Nts. All these results are summarized in Table III.

The Raman band at $1206 \mathrm{~cm}^{-1}$ is assigned to the vibration of the $C 2$ '-endo sugar pucker of dT and is known as a sensitive marker of local conformational transitions involving thymine bases. ${ }^{29}$ Our spectra show that the bis-Nt binding induces a downshift of this band. This shift is most likely caused by a discrete conformation change of the dT sugar pucker of the 0,2'endo conformation. $^{29}$ Thereby, bis-Nt also affects the conformation of the OLIGs within the bis-Nt specific sequences. A precise value of the downshift was not estimated because of the weak intensity of the bands considered in the spectra of the bisNts-DNA complexes. However, it is clear that the largest shift is induced by DNA binding of the bis- $\mathrm{Nt}(<->)$ if compared to the bis- $\mathrm{Nt}(-><-)$ and bis$\mathrm{Nt}(->->)$-DNA complexes.

The bands of the DNA phosphate groups at 790 $\mathrm{cm}^{-1}$ are known to be classical markers of the DNA secondary structure and are routinely used for identification of the A, B, or Z forms of DNA. ${ }^{26}$ Bis-Nt(<->)-OLIG3 binding induced a $3 \mathrm{~cm}^{11}$ downshift of this band. No changes of this band

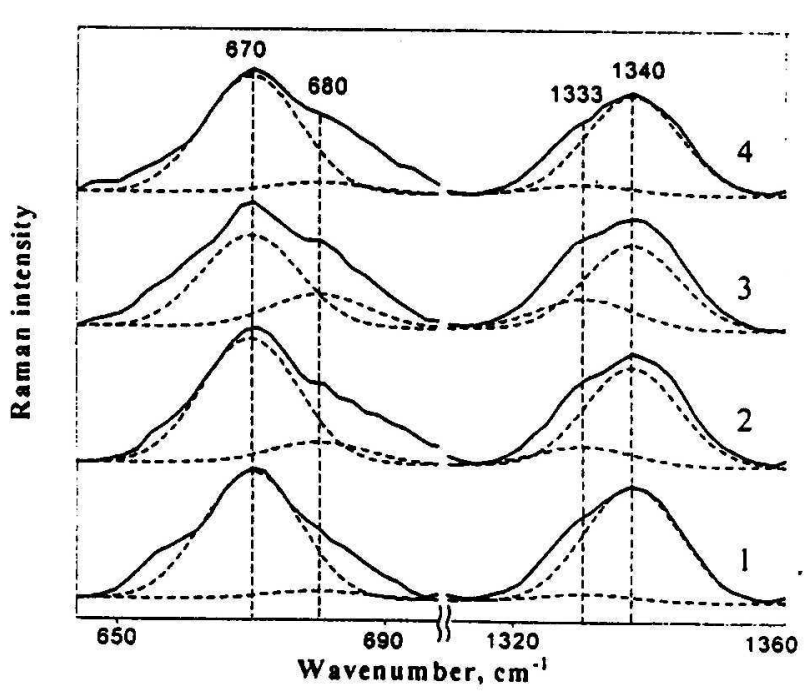

Figure 6. The decomposition of the 650-690 and $1320-1360 \mathrm{~cm}^{-1}$ spectral regions of Raman spectra of bis-Nt-OLIG complexes. Only those sensitive to the alterations of the $\mathrm{dG}$ furanose ring pucker bands are shown. The spectra are shown for unbound OLIGI (spectrum 1), bis-Nt(↔)-OLIG1 complex (spectrum 2), bis-Nt $\rightarrow \leftarrow$ )-OLIG1 complex (spectrum 3 ), and bis$\mathrm{Nt}(\rightarrow \rightarrow)$ OLIG1 complex (spectrum 4). 
were found for bis-Nt $(<->)$ bound to the OLIG1 or OLIG2 and for bis-Nt(-»«-) and bis-Nt(-»-») complexed to any of the oligonucleotides. Thus, modifications of the OLIG3 secondary structure induced by bis-Nt(<->) correlated with the ability of this derivative to induce the strongest perturbations within the structure of the OLIG3 revealed in the other spectral regions. Hence, bis-Nt $(<->)$ may be characterized as the derivative with the strongest DNA structure perturbation.

A downshift of the adenine vibration band near $725 \mathrm{c} \mathrm{m}^{-1}$ (see Ref. 31) was seen in the spectra of bis-Nt(<->)-OLIG complexes only. The value of the shift was about $2-:-3 \mathrm{~cm}^{-1}$. This shift was likely caused by changes in the stacking interaction, which was due to slight variations of the backbone parameters.

The following conclusions were drawn after analysis of all the spectral data presented:

1. All DNA structural modifications induced by binding of the bis-Nts are of a local nature, being within the range of general B-form conformational characteristics. Despite the strong AT specificity of bis-Nts for DNA binding, pronounced DNA local structural alterations involving the guanine bases were detected. Consequently, the DNA structural perturbations involved not only the sequences corresponding to bis- $\mathrm{Nt}$ binding sites, but also sequences apart.

2. The strongest perturbations in the DNA structure were induced by bis-Nt(<->). This effect may have been caused by the presence of a relatively rigid linker in bis$\mathrm{Nt}(<->)$ versus the other bis-Nts used in the study. The strongest changes in the DNA were observed when bis-Nts were in complex with the nonspecific OLIGs.

3. Binding of bis-Nts did not change the backbone parameters of the OLIGs found in a classical B conformation. The spectra of free OLIGs in solution and those of their complexes with bis-Nts both contain the invariable B-form marker bands $\left(838 \mathrm{~cm}^{-1}\right.$ for the $-0-\mathrm{P}-0-$ antisymmetric stretch and $1090 \mathrm{~cm}^{-1}$ for the $\mathrm{PO}_{2}^{-}$symmetric stretch).
Moreover, each of the OLIGs contains the sequence that allows formation of the complex with one of the bis-Nts with an at least 10-fold bigger binding constant (specific binding) compared to the other bis-Nts (nonspecific binding).

Raman spectroscopy shows that the specificity of DNA binding of bis-Nts is determined by mutual stereoconformity of bis-Nt to the topology of specific sequences of the OLIG. Mechanically, DNA binding by the bis-Nts is accompanied by conformational distortions of both the ligand and the OLIG. Furthermore, the structural modification of the OLIG induced by bis-Nt binding appears not only in a bis-Nt binding site, but also in the sequences quite apart from these sites. In the bis-Nt molecule the torsion angles of the peptide bonds (Fig. 1) is varied, resulting in a bend of each of the two Nt fragments and adapting them to the form of the OLIG's minor groove. Moreover, the most prominent structural changes of bis-Nts and OLIGs were observed for the nonspecific binding of bis-Nts.

The Raman spectra reveal several conformational changes in the OLIGs, including slight modifications of the OLIG secondary structure (alterations of the valence symmetric vibration band of $-0-\mathrm{P}-0-$ groups at $790 \mathrm{~cm}^{-1}$ ), perturbations of the stacking interactions of adenine $\left(725 \mathrm{~cm}^{-1}\right)$, and local changes in the topology of the backbone around the thymines $\left(1206 \mathrm{~cm}^{-1}\right)$ and guanines $\left(670-:-680 \mathrm{~cm}^{-1}\right)$. It should be noted that the changes of the bands in the 670 -:- $680 \mathrm{~cm}^{-1}$ region are the most important because they indicate conformation of the OLIGs in the vicinity of bis-Nt specific sequences.

The differences in the molecular mechanism of DNA binding by bis-Nts may account for their capacity to inhibit the catalytic activities of different DNA-binding enzymes. Indeed, our experiments on the influence of these bis-Nts on the activity of human DNA topoisomerase I showed that ligands with different orientations of $\mathrm{Nt}$ fragments modulate the enzyme activity in different ways. $^{\mathbf{1 4}}$

The second author (A.S.) is supported by an ARC fellowship.

\section{REFERENCES}

1. Zimmer, C; Wahnert, U. Prog Biophys Mol Biol 1986, 47, 31-112.

2. Zasedatelev, A. S.; Zhuze, A. L.; Zimmer, C; 
Grokhovsky, S. L.; Tumanyan, V. G.; Gursky, G. V.; Gottikh, B. P. Dokl Akad Nauk SSSR 1976, 231, 1006-1009.

3. Gursky, G. V.; Tumanyan, V. G.; Zasedatelev, A. S.; Zhuze, A. L.; Grokhovsky, S. L.; Gottikh, B. P. In Nucleic Acid-Protein Recognition; Vogel, H. J., Ed.; Academic: New York, 1977; pp 189-217.

4. Kopka, M. L; Yoon, C; Goodsell, D.; Pjura, P.; Dickerson, R. E. Proc Natl Acad Sci USA 1985, 82, 1376-1380.

5. Coll, M.; Frederick, C. A.; Wang, A. H.-J.; Rich, A. Proc Natl Acad Sci USA 1987, 84, 8385-8389.

6. Patel, D. J.; Shapiro, L. J Biol Chem 1986, 261, 1230-1240.

7. Klevit, R. E.; Wemmer, D. E.; Reid, B. R. Biochemistry 1986, 25, 3296-3303.

8. Pelton, J. G.; Wemmer, D. E. Biochemistry 1988, 27, 8088-8096.

9. Khorlin, A. A.; Krylov, A. S.; Grokhovsky, S. L.; Zhuze, A. L.; Zasedatelev, A. S.; Gursky, G. V.; Gottikh, B. P. FEBS Lett 1980, 118, 311-314.

10. Khorlin, A. A.; Grokhovsky, S. L.; Zhuze, A. L.; Gottikh, B. P. Bioorg Khim 1982, 8, 1358-1364.

11. Gursky, G. V.; Zasedatelev, A. S.; Zhuze, A. L.; Khorlin, A. A.; Grokhovsky, S. L.; Streltsov, S. A.; Surovaya, A. N.; Nikitin, S. M.; Krulov, A. S.; Retchinsky, V. O.; Mikhailov, M. V.; Beabealashvili, R. S.; Gottikh, B. P. Cold Spring Harbor Symp Quantum Biol 1983, 47, 367-378.

12. Griffin, J. H.; Dervan, P. B. J Am Chem Soc 1986, 108, 5008-5009.

13. Neamati, N.; Mazumder, A.; Sunder, S.; Owen, J. M.; Tandon, M.; Lown, J. W.; Pommier, Y. Mol Pharmacol 1998, 54, 280-290.

14. Sukhanova, A.; Grokhovsky, S.; Zhuze, A.; Roper, D.; Bronstein, I. Biochem Mol Biol Int 1998, 44, 997-1010.

15. Lown, J. W.; Krowicki, K; Balzarini, J.; Newman, R. A.; De Clercq, E. J Med Chem 1989, 32, 2368 2375.
16. Grokhovsky, S. L.; Gottikh, B. P.; Zhuze, A. L. Bioorg Khim 1992, 18, 570-583.

17. Grokhovsky, S. L.; Surovaya, A. N.; Burckhardt, G.; Pismensky, V. F.; Chernov, B. K; Zimmer, C; Gursky, G. V. FEBS Lett 1998, 439, 346-350.

18. Grokhovsky, S. L.; Gottikh, B. P.; Zhuze, A. L. Bioorg Khim, to appear.

19. Sambrook, J.; Fritsch, E. F.; Maniatis, T. Molecular Cloning. A Laboratory Manual; Cold Spring Harbor Laboratory Press: Cold Spring Harbor, NY, 1989.

20. Ianoul, A.; Fleury, F.; Duval, O.; Waigh, R.; Jardillier, J. C; Alix, A. J. P.; Nabiev, I. J Phys Chem 1999, 103, 2008-2013.

21. Cozzarelli, N. R., Wang, J. C, Eds. DNA Topology and Its Biological Effects; Cold Spring Harbor Laboratory Press: Cold Spring Harbor, NY, 1990.

22. Martin, J. C; Wartell, R. M.; O'Shea, D. C. Proc Natl Acad Sci USA .1978, 75, 5483-5487.

23. Grygon, C. A.; Spiro, T, G. Biochemistry 1989, 28, 4397-4402.

24. Nabiev, I.; Sokolov, K; Manfait, M. In Biomolecular Spectroscopy, Part A; Clark, R. J. H., Hester, R. E., Eds.; Wiley: Chichester, U.K, 1993; pp 267-338.

25. Feofanov, A.; Ianoul, A.; Krukov, E.; Maskevich, S.; Vasiliuk, G.; Kivach, L.; Nabiev, I. Anal Chem 1997, 69, 3731-3740.

26. Prescott, B.; Steinmetz, W.; Thomas, G. J., Jr. Biopolymers 1984, 23, 235-256.

27. Grokhovsky, S. L.; Zubarev, V. E. Nucl Acids Res 1991, 19, 257-264.

28. Kopka, M. L.; Yoon, C; Goodsell, D.; Pjura, P.; Dickerson, R. E. J Mol Biol 1985, 183, 553-563.

29. Benevides, J. M.; Wang, A. H.-J.; van der Marel, G. A.; van Boom, J. H.; Thomas, G. J., Jr. Biochemistry 1988, 27, 931-938.

30. Kryukov, E.; Sukhanova, A.; Grokhovsky, S.; Zhuze, A.; Nabiev, I. Mol Biol 1999, 33, 462-470.

31. Wartell, R. M.; Harrell, J. T. Biochemistry 1986, 25, 2664-2671. 